\title{
Formation Process and Properties of Phytic Acid Conversion Coatings on Magnesium
}

\author{
Jian-Rui Liu, Yi-Na Guo, Wei-Dong Huang \\ State Key Laboratory of Solidification Processing, Northwestern Polytechnical University, Xi'an, P. R. China \\ Email: 1jr@nwpu.edu.cn \\ Received March $7^{\text {th }}, 2011$; revised March 10 $0^{\text {th }}, 2011$; accepted March $16^{\text {th }}, 2011$.
}

\begin{abstract}
A chromium-free conversion coating treatment for magnesium by phytic acid solution was studied. The formation process of phytic acid conversion coating was studied through measuring the open circuit potential (OCP) and weight change of the pure magnesium in the different conversion treatment time. The morphologies and compositions of the coatings were determined by SEM and EDS respectively. The conversion coating has the multideck structure with netlike morphology which is similar to the chromate conversion coating, and is mainly composed of $\mathrm{Mg}, \mathrm{P}, \mathrm{O}$ and $\mathrm{C}$. The contents of $C$ and $P$ and the size of the cracks in different layers decrease from the external layer to the inner layer. The hydroxyl groups and phosphate carboxyl groups in the coating which have the similar properties to organic paintcoat are beneficial to the combination of substrate and organic paintcoat. The formation mechanism and thickness variation of the conversion coatings are also discussed.
\end{abstract}

Keywords: Magnesium, Chemical Conversion Coatings, Phytic Acid, Formation Mechanism

\section{Introduction}

As the lightest structural alloys, magnesium alloys are attractive for automotive and aerospace applications to achieve significant reduction in energy conservation and green-house gas emission because of its good combination of mechanical properties and castability. However, the poor corrosion resistance of magnesium alloys which results from the properties of metal magnesium is one of the critical factors limiting its wide applications, especially in an environment containing corrosive ingredients [1-3]. Surface treatments can improve the corrosion resistance of magnesium and its alloys, which have been extensive researched in recently years [4]. In the surface treatment methods, Chemical conversion treatment is an effective and simple method, such as chromate [5], permanganate [6], phosphate $[7,8]$, phosphate/permanganate $[9,10]$, etc. Chromate conversion treatment as a conventional chemical conversion method, it has been widely used in industry for long time. But the conversion solution containing toxic hexavalent chromium carcinogen is harmful to the environment, which has been restricted and forbidden in many countries. The pollution level of the treatment solutions containing phosphate or permanganate is less than that of chromate, although the metal ions and $\mathrm{PO}_{4}^{3-}$ existing in the solutions have certain harmfulness to environment. Therefore it is urgently needed to develop new environment-friendly surface treatments for magnesium and its alloys.

Phytic acid $\left(\mathrm{C}_{6} \mathrm{H}_{18} \mathrm{O}_{24} \mathrm{P}_{6}\right.$, inositol hexaphosphate ester), an innocuity macromolecule natural compound with 24 oxygen atoms, 12 hydroxyl groups and 6 phosphate carboxyl groups, is extensively applied in the area of surface protection of metals due to its particular physical and chemical properties which has powerful capability of chelating with many metals ions $[11,12]$. The researches [13-16] indicate that the chemical conversion coatings based on phytic acid solution have better corrosion resistance for magnesium alloys, which can substitute for those harmful methods. It can be seen from these research results that the properties of conversion coatings are closely related to their microstructure and compositions, which greatly depend on the conversion treating parameters such as treating time, temperature and concentration of the solution.

In order to further know the formation mechanism of phytic acid conversion coating and the influence of processing parameters on the microstructure and corrosion resistance of the chemical conversion coating, in this study, the formation process of the phytic acid conversion coating was investigated by electrochemical and 
weighting method. The detailed micro morphology evolution of the conversion coating during the treatment procedure was also examined. Furthermore, the microstructure and the corrosion procedure of the conversion coating were studied by scanning electron microscopy (SEM) and electron energy spectrum (EDS). The experimental results could provide theoretical references for the analysis and study of phytic acid conversion coating formed on magnesium alloys to accelerate the application of phytic acid in the surface protection of magnesium alloys in the future.

\section{Experimental}

\subsection{Conversion Treating Procedure}

The magnesium used in this study was commercial magnesium ingot, and its main compositions are (in $w \mathrm{t} \%$ ): $\mathrm{Mg}>$ 99.95, $\mathrm{Al} 0.009$, Mn 0.0055, Fe 0.0027, Cu 0.0022, $\mathrm{Ni} 0.0004, \mathrm{Si}<0.01$. Phytic acid and $\mathrm{NaCl}$ used here were analytical reagent, and the water was de-ionized water.

The Magnesium ingots were cut into cubic specimens with the dimension of $10 \times 10 \times 10 \mathrm{~mm}^{3}$. Each cube was embedded into epoxy resin with only one side of exposure as the working area. Then the working area was polished with grade 600 and grade 1000 carborundum papers, cleaned with de-ionized water and acetone, dried in hot air. After that, the specimens were immersed in phytic acid solution to obtain phytic acid conversion coating on their surface. Subsequently, the samples were taken out, rinsed by floating de-ionized water, and dried at room temperature. The weight of the sample was measured by an electronic balance with an accuracy of $0.1 \mathrm{mg}$ during the conversion treatment process.

\subsection{Characterization}

The surface morphology of the conversion coating was observed on a scanning electron microscopy (SEM, Model Discoverer S570, made by Hitachi Company of Japan). Meanwhile the compositions of the coating were characterized using the energy dispersive spectrum (EDS, Model Discoverer S360, made by Cambridge Company of UK). Corrosion properties of the conversion coatings in neutral $3.5 \mathrm{wt} \% \mathrm{NaCl}$ solutions were measured using the immersion experiments.

The Open Circuit-potential curve used to study the formation mechanism of the conversion coatings on magnesium were measured using CHI600B electrochemical workstation at $20 \pm 1^{\circ} \mathrm{C}$. Measurements were conducted in the phytic acid solution using a traditional three-electrode system, a saturated calomel electrode (SCE) was used as reference electrode, a platinum (Pt) was used as auxiliary electrode, and the sample was used as working electrode.

\section{Results and Discussion}

\subsection{Formation Process of Phytic Acid Conversion Coating}

The formation process of phytic acid conversion coating was studied by detecting the open circuit potential (OCP) and weight change of the pure magnesium in the different conversion treatment time. Figure 1 shows the open circuit potential-time curve and weight-time curve of pure magnesium immersed in $0.5 \mathrm{wt} \%$ phytic acid solution under $\mathrm{pH}=3$ at $25^{\circ} \mathrm{C}$. It can be seen from Figure 1(a) that the OCP of the specimen increased during the whole conversion treatment procedure from approximately $-2.20 \mathrm{~V}$ to about $-2.05 \mathrm{~V}$, which proved that a phytic acid conversion coating formed on the surface of magnesium. In the first $1600 \mathrm{~s}$, the OCP of magnesium presented a relatively swift increase and accompanied by the intense formation of hydrogen, which indicated the phytic acid conversion coating was forming quickly during this period. As can be seen, the OCP of the magnesium

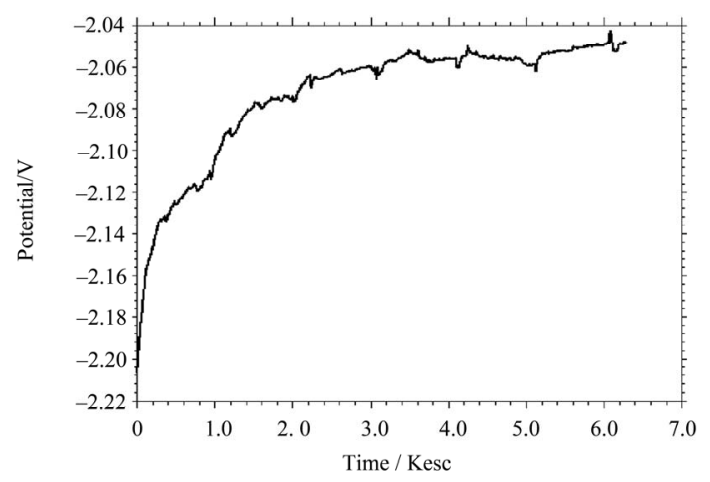

(a)

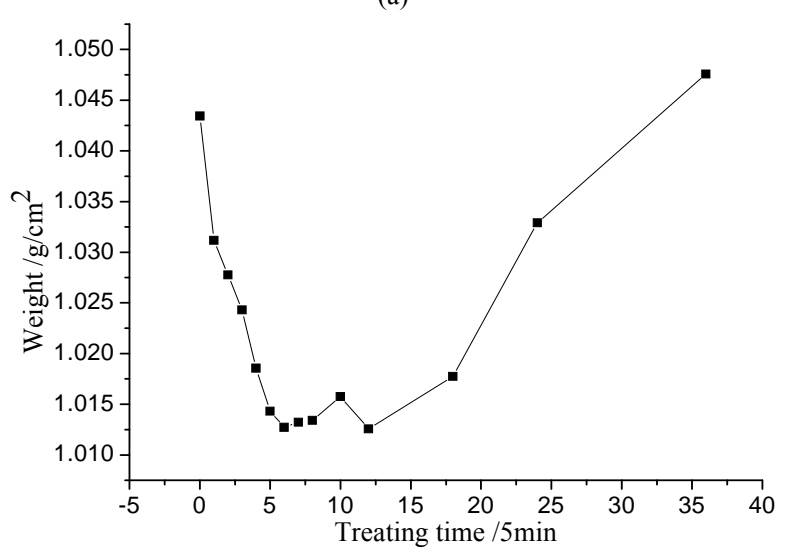

(b)

Figure 1. Phytic acid conversion coating on magnesium surface during the conversion treatment processing. (a) Open circuit potential-time curve; (b) Weight gain to time curve. 
after $1600 \mathrm{~s}$ became relative stabilization. It suggested that after $1600 \mathrm{~s}$, the transmission of ions and the release of hydrogen were restrained as the conversion coating had basically formed, which result in the formation speed slowing up of the coating. The potential fluctuation of OCP during this period was due to the formation and exfoliation of the coating. It can be seen from Figure 1(b) that the weight of specimen decreased markedly before the first $1500 \mathrm{~s}$, then tended to remain constant from $1500 \mathrm{~s}$ to $4500 \mathrm{~s}$, after that, it began to recover. The decrease of specimen's weight at first can be attributed to the reasons. Firstly, $\mathrm{Mg}$ dissolves in the acidic solution forming $\mathrm{Mg}^{2+}$ ions. Secondly, in the beginning, the deposition rate of magnesium phytate compounds is not as quick as the ionization rate of magnesium. The magnesium phytate compounds begin deposition on the substrate surface to form conversion coating when the concentration of magnesium phytate compounds in solution achieves a certain level. The slight weight change between $1500 \mathrm{~s}$ and $4500 \mathrm{~s}$ suggests that the whole reaction system reaches dynamic equilibrium, a relatively thick conversion coating forms during this period. After that, the transmission of magnesium ions becomes very difficult because of the coating. As a result, the effect of the deposition of magnesium phytate compounds on specimen's weight change turns to be more obvious.

Figure 2 shows the SEM micrographs of the coatings formed in different times. It displays the evolution of the phytic acid conversion coating during treatment process. Seeing from Figure 2(a), there were some white flocs formed and distributed non-uniformly on the surface of specimen. The chemical components of the flocs were consisted of $\mathrm{C}, \mathrm{P}, \mathrm{O}$ and $\mathrm{Mg}$ through EDS analysis, which indicated that the white flocs were magnesium phytate compounds. As treatment time prolonged, the white flocs increased and connected with each other to form a relative uniformity films of magnesium phytate on the specimen surface. As can be seen from Figures 2(b,c), the thickness of the layer was so thin at this moment that the polishing trace could be seen.

Seeing from Figure 2(d), when the treatment time reached $5 \mathrm{~min}$, an integral coating with some meshy cracks on it was formed on the specimen, which was similar with other kinds of conversion coatings $[17,18]$. The grinding trace couldn't be seen there, which suggested that the phytic acid conversion coating became comparatively thick and flat. Additionally, it was notable that magnesium phytate compounds still existed on the surface of specimen. After $5 \mathrm{~min}$, it can be seen that the crack quantity of the conversion coating decreased with the increase of treatment time (Figures 2(e-h)). The conversion coating remained the "dry-mud" morphology all the time. The quantity and magnitude of the cracks changed with the variation of the processing parameters. The cracks could become very small if the specimen was treated under the suitable processing parameters.

\subsection{The Mechanism Analysis of Phytic Acid Conversion Coating Forming}

Phytic acid is a large molecular polyatomic acid com-

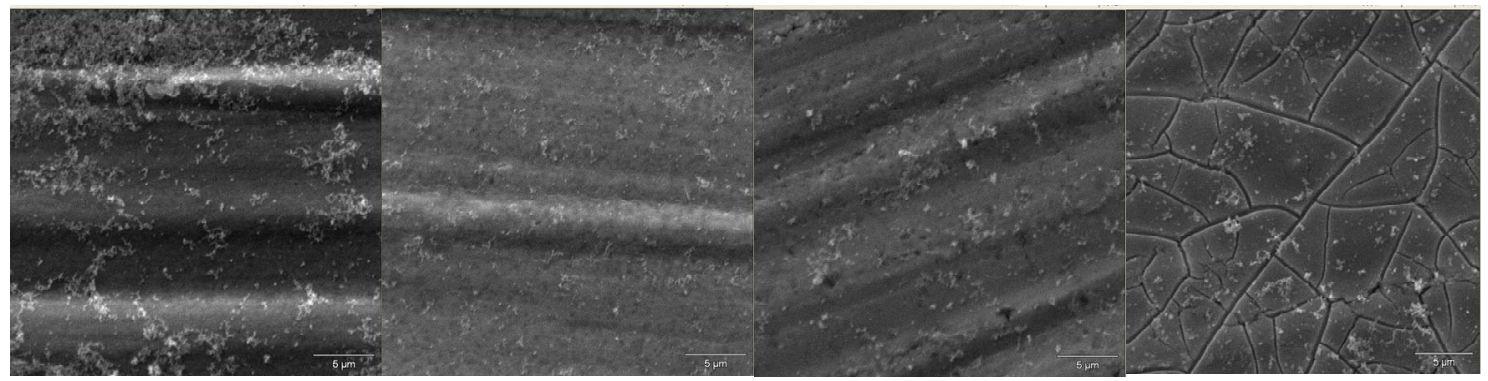

(a) $5 \mathrm{~s}$

(b) $20 \mathrm{~s}$

(c) $1 \mathrm{~min}$

(d) $5 \mathrm{~min}$

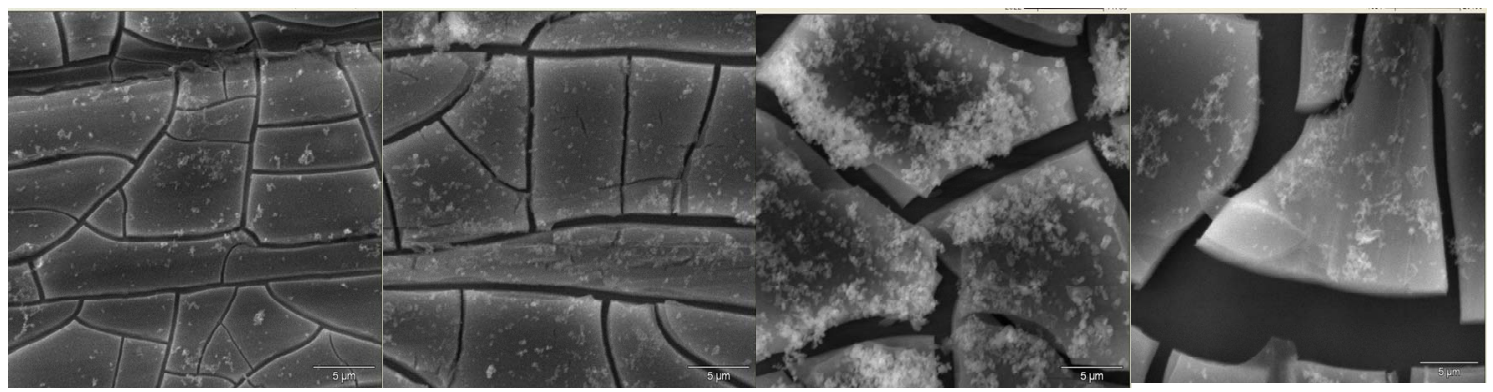

(e) $10 \mathrm{~min}$

(f) $30 \mathrm{~min}$

(g) $40 \mathrm{~min}$

(h) $60 \mathrm{~min}$

Figure 2. The surface SEM morphologies of the specimen treated in the bath containing $0.5 \mathrm{wt} \%$ phytic acid under $\mathrm{pH}=3$ at $25^{\circ} \mathrm{C}$ for different time. 
pound. It may present multilevel ionization in water as follows [16]

$$
\begin{array}{r}
\mathrm{RH}_{12}+\mathrm{H}_{2} \mathrm{O}=\mathrm{RH}_{11}^{-}+\mathrm{H}_{3} \mathrm{O}^{+} \\
\mathrm{RH}_{11}^{-}+\mathrm{H}_{2} \mathrm{O}=\mathrm{RH}_{10}^{2-}+\mathrm{H}_{3} \mathrm{O}^{+} \\
\\
\ldots \ldots . . \\
\mathrm{RH}^{11-}+\mathrm{H}_{2} \mathrm{O}=\mathrm{R}^{12-}+\mathrm{H}_{3} \mathrm{O}^{+}
\end{array}
$$

Here $\mathrm{R}$ refers to $\mathrm{C}_{6} \mathrm{H}_{6} \mathrm{O}_{6}\left(\mathrm{PO}_{3}\right)_{6}$. The ionization degree of phytic acid depends on the $\mathrm{pH}$ values of the solution. At the same time of phytic acid ionization, the element $\mathrm{Mg}$ on substrate surface occur anodic reaction. Mg dissolves in the solution forming $\mathrm{Mg}^{2+}$.

$$
\mathrm{Mg}-2 \mathrm{e} \rightarrow \mathrm{Mg}^{2+}
$$

The $\mathrm{H}_{3} \mathrm{O}^{+}$in solution happen cathode reaction with the electrons of $\mathrm{Mg}$ releasing to form hygrogen escaping.

$$
2 \mathrm{H}_{3} \mathrm{O}^{+}+2 \mathrm{e} \rightarrow 2 \mathrm{H}_{2} \mathrm{O}+\mathrm{H}_{2} \uparrow
$$

$\mathrm{The}^{2+}$ ions react with phytate groups to form magnesium phytate compounds.

$$
\mathrm{RH}_{10}^{2-}+\mathrm{Mg}^{2+} \rightarrow \mathrm{MgRH}_{10}
$$

When the concentration of insoluble magnesium phytate compounds reached a certain level, it gradually deposited on the surface of magnesium substrate forming the discrete flocs. With the deposit increase, the discrete flocs combined each other through chemiadsorption effect to form the continuous conversion coatings. The conversion coatings are interlaced with each other, because one of the six phosphate carboxyl groups in phytic acid locates in $\boldsymbol{a}$ place and the others locate in $\boldsymbol{e}$ place, among them four of which are in the same level. This kind of coating is relatively more compact than the natural oxide film. So it can effectively insulate the contact of magnesium substrate and environment media, and improve the corrosion resistance of magnesium and its alloys.

\subsection{The Morphology and Composition of Phytic Acid Conversion Coating}

Infrared absorption spectroscopy method was conducted to further investigate the chemical composition of the conversion coating, and the result is shown in Figure 3. Seeing from Figure 3, the strong and wide absorption peak at $3392.38 \mathrm{~cm}^{-1}$ was attributable to hydroxyl group, the band at $1646.81 \mathrm{~cm}^{-1}$ was probably due to the carboxyl group, and the band at $1052.33 \mathrm{~cm}^{-1}$ was assigned to the phosphate radical or hydrogen phosphate radical. The result confirmed further that the conversion coating was formed mainly by the deposition of the magnesium phytate compounds. The phytic acid conversion coatings have the similar properties with organic paintcoat because of the hydroxyl groups and phosphate carboxyl groups, which are beneficial to the combination of substrate and organic coating.

Figure 4 exhibits the transverse section and the line scan of the phytic acid conversion coating formed in solution containing $0.5 \%$ phytic acid at $25^{\circ} \mathrm{C}$ and $\mathrm{pH}=3$ for 30min. It can be seen from Figure 4(a) that the conversion coating was compact and well connected with magnesium substrate. Seeing from Figures 4(b-e), the content of $\mathrm{Mg}$ reached its minimum level at the interface between substrate and conversion coating. The changes of the content of $\mathrm{C}, \mathrm{P}$ and $\mathrm{O}$ were similar to each other, all of them increased at the interface between substrate and conversion coating, and then reached the peaks. The slight increase of the content of $\mathrm{C}, \mathrm{P}$ and $\mathrm{O}$ at the interface can be explained that the compounds of the conversion coating were embed into the aperture between the

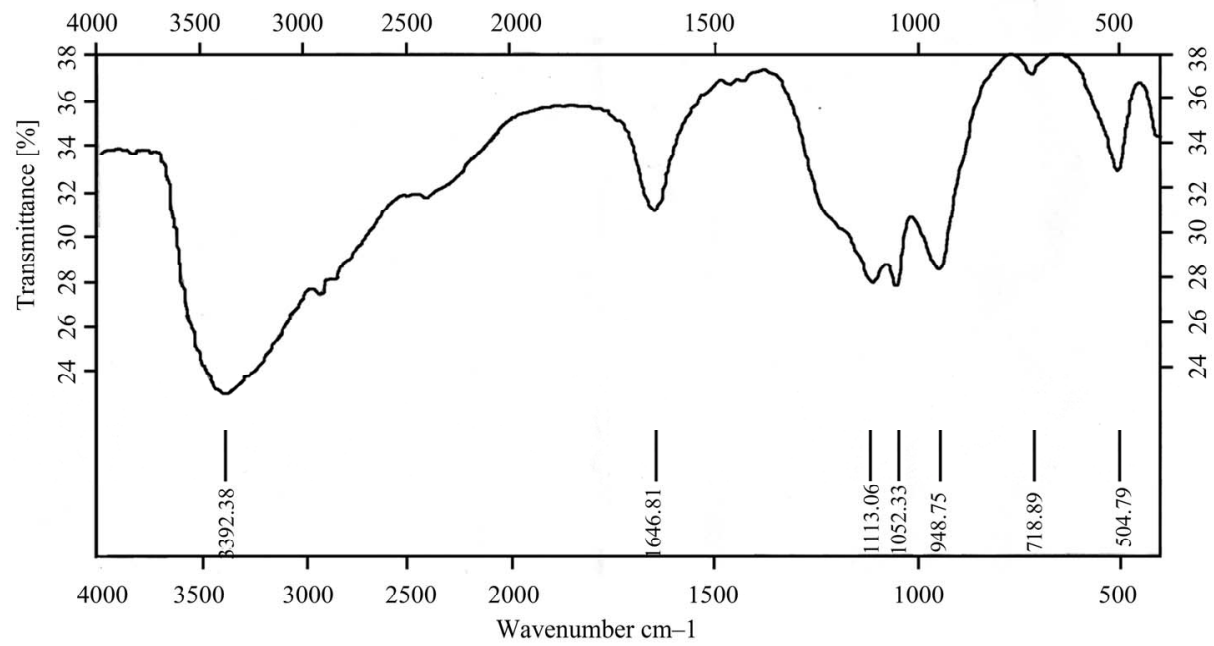

Figure 3. Infrared absorption spectroscopy of the phytic acid and magnesium formed compound. 

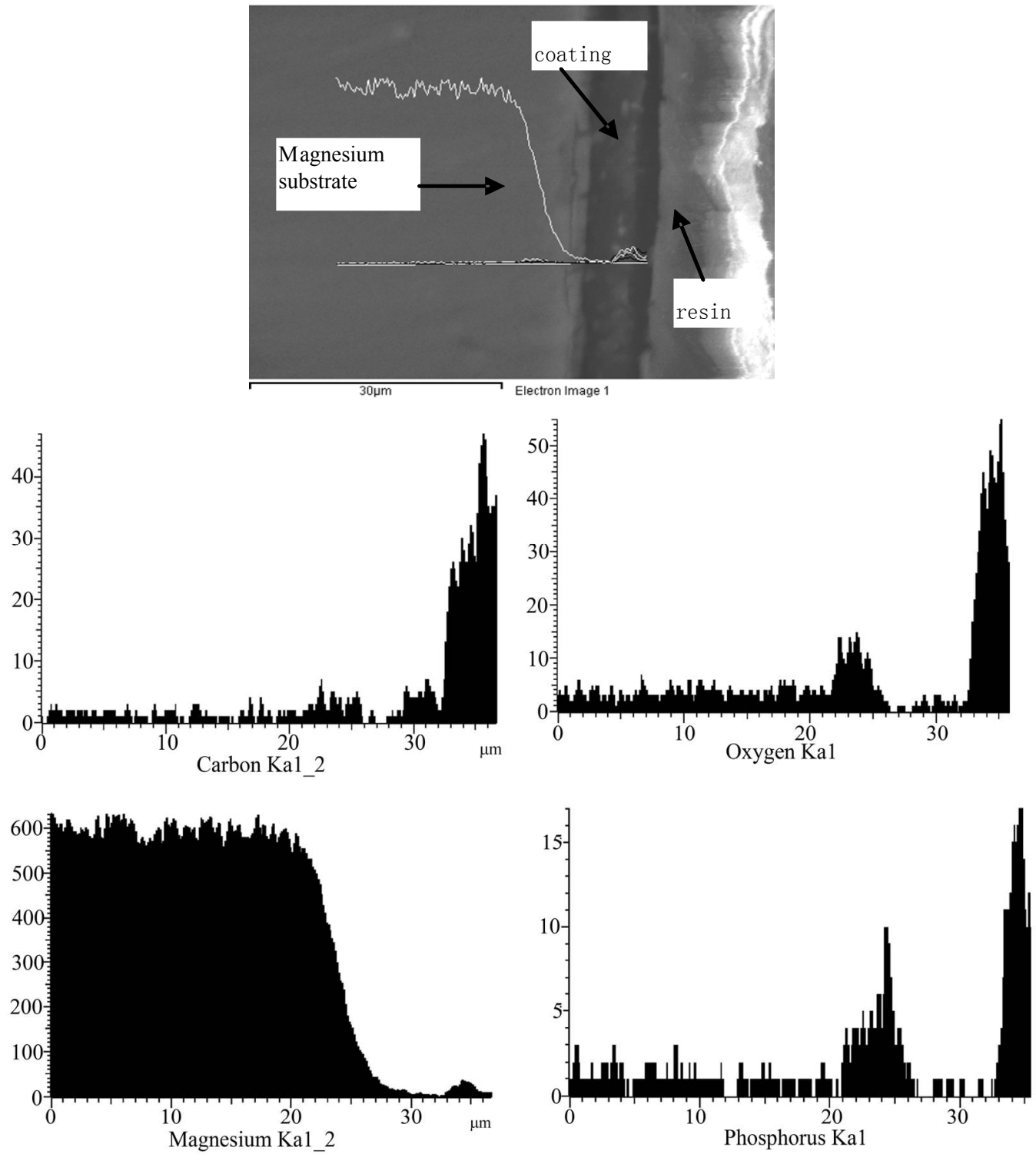

Figure 4. Distribution of X-ray intensity of each element detected by electron microprobe analysis (EMA) in the magnesium substrate and the conversion coating formed in solution containing $0.5 \mathrm{wt}$. $\%$ phytic acid at $25^{\circ} \mathrm{C}$ under $\mathrm{pH}=3$

substrate and the conversion coating when the sample was grinded. The thickness of the conversion coating varied from $1.0 \mu \mathrm{m}$ to $15 \mu \mathrm{m}$ based on the processing parameters.

The above sample with the phytic acid conversion coating had been immersed in the $3.5 \mathrm{wt} \% \mathrm{NaCl}$ solution for $120 \mathrm{~h}$, then taken out, washed with distilled water, dried at room temperature and finally analyzed by SEM and EDS again. The results are shown in Figure 5 and Table 1. It can be seen from Figure 5 that the conversion coating after immersion became more disorganized, and showed multideck structure. In addition, the cracks existed anywhere and the size of them became smaller from the external layer to the inner layer. In Figure 5, points 1, 2 and 3 denoted the different locations from the inner layer to the external layer. The analysis results of element content for the three points by EDS were listed in Table 1. Seeing from Table 1, the different layers of corroded conversion coating were also mainly consisted of $\mathrm{C}, \mathrm{P}, \mathrm{O}$ and $\mathrm{Mg}$. But the content of the same element was distinct in different locations. The content of $\mathrm{Mg}$ and $\mathrm{O}$ increased gradually from the external layer to the inner layer, among them the mass percentage of $\mathrm{O}$ changed slightly. On the contrary, the content of $\mathrm{C}$ and $\mathrm{P}$ gently decreased from the external layer to the inner layer. The reason of this phenomenon is that once a conversion 
Table 1. The The content of $\mathrm{C}, \mathrm{O}, \mathrm{P}$ and $\mathrm{Mg}$ in the different points by EDS.

\begin{tabular}{|c|c|c|c|c|c|c|}
\hline \multirow{2}{*}{ Element } & \multicolumn{3}{|c|}{ Element/wt\% } & Atom $/ \%$ & \multirow[b]{2}{*}{2} & \multirow[b]{2}{*}{3} \\
\hline & 1 & 2 & 3 & 1 & & \\
\hline $\mathrm{C}$ & 5.74 & 13.64 & 19.36 & 9.23 & 20.8 & 30.67 \\
\hline $\mathrm{O}$ & 43.33 & 41.99 & 30.94 & 52.30 & 48.19 & 36.79 \\
\hline $\mathrm{Mg}$ & 40.74 & 29.22 & 12.58 & 32.37 & 22.07 & 9.85 \\
\hline $\mathrm{P}$ & 7.04 & 13.89 & 35.66 & 4.39 & 8.24 & 21.91 \\
\hline
\end{tabular}

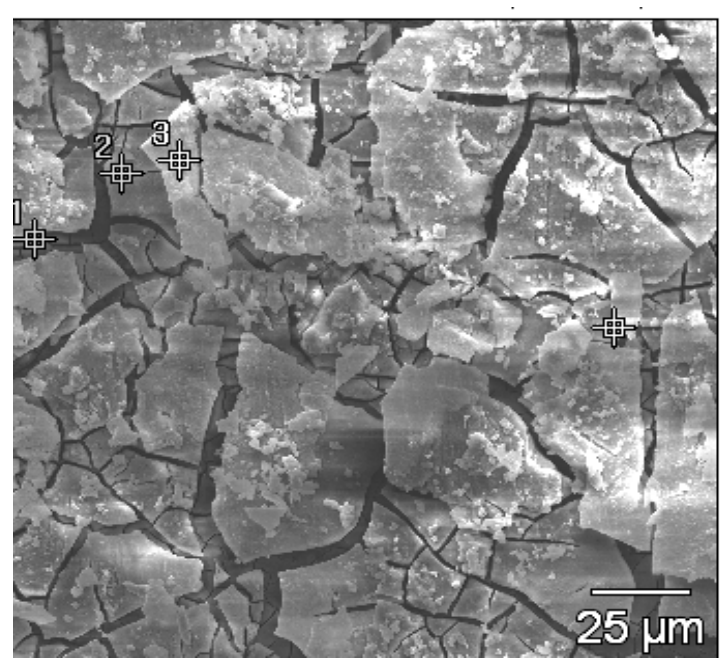

Figure 5. Surface morphology of the conversion coating corroded in $3.5 \mathrm{wt} \% \mathrm{NaCl}$ solution for $120 \mathrm{~h}$.

coating was formed on the surface of magnesium, it would become difficult that the phytic acid molecules or anions in the solution diffused to the inside of the layer and reacted with the substrate. It can be inferred that the cracks of the conversion coating did not stretch to the substrate of magnesium according to the component of the point in the inner layer (point 1). This indicated that the conversion coating could prevent magnesium from being corroded farther.

The multideck structure of the conversion coating was closely related to the forming of the cracks. The phytic acid molecules or anions in the solution could pass the conversion layer easily to react and form multideck structure because of the cracks in the conversion coating.

There were two possible reasons for the cracks of the conversion coating. Firstly, the amount of hydrogen would form because of the reaction between magnesium and phytic acid during the conversion treatment. The hydrogen transiting the surface layers resulted in the formation of cracks. Secondly, in the process of drying, the evaporation of water in the conversion coating gradually caused the stress to make the cracks.

The experimental results indicated that as the time of the conversion coating being immersed in the $3.5 \mathrm{wt} \%$ $\mathrm{NaCl}$ solution increased, the external layer of conversion coating gradually fell off and the inner layer would ex- pose. However, the inner layer was also effectively protective, because the size and quantity of cracks on it were relatively small.

\section{Conclusions}

Phytic acid conversion coating has the multideck structure with netlike morphology which is similar to the chromate conversion coating. The elements of every layer are mainly composed of $\mathrm{Mg}, \mathrm{P}, \mathrm{O}$ and $\mathrm{C}$. The contents of $\mathrm{C}$ and $\mathrm{P}$ and the size of the cracks in the layer decrease from the external layer to the inner layer. The hydroxyl groups and phosphate carboxyl groups in the coating which have the similar properties with organic paintcoat are beneficial to the combination of substrate and organic paintcoat. The thickness of the conversion coating varies from $1.0 \mu \mathrm{m}$ to $15 \mu \mathrm{m}$ according to the processing parameters.

\section{Acknowledgements}

This work was supported by the Research Fund of the State Key Laboratory of Solidification Processing (NWPU) (Grant Nos. 29-T-2009).

\section{REFERENCES}

[1] Z. H. Chen, H. G. Yan, J. H. Chen, Y. J. Quan, H. M. Wang and D. Chen, "Magnesium Alloys," Chemical Industry Press, Beijing, 2004.

[2] G. Baril and N. Pehere, "The Corrosion of Pure Magnesium in Aerated and Deaerated Sodium Sulphate Solutions," Corrosion Science, Vol. 43, No. 3, March 2001, pp. 471-484. doi:10.1016/S0010-938X(00)00095-0

[3] F. C. Liu, W. Liang, X. R. Li, X. G. Zhao, Y. Zhang and H. X. Wang, "Improvement of Corrosion Resistance of Pure Magnesium via Vacuum Pack Treatment," Journal of Alloys and Compounds, Vol. 461, No. 1-2, August 2008, pp. 399-403. doi:10.1016/j.jallcom.2007.06.097

[4] J. E. Gray and B. Luan, "Protective Coatings on Magnesium and its Alloys-A Critical Review," Journal of Alloys and Compounds, Vol. 336, No. 1-2, April 2002, pp. 88-113. doi:10.1016/S0925-8388(01)01899-0

[5] H. Zhang, G. C. Yao, S. L. Wang, Y. H. Liu and H. J. Luo, "A Chrome-Free Conversion Coating for MagnesiumLithium Alloy by a Phosphate-Permanganate Solution," Surface and Coatings Technology, Vol. 202, No. 9, February 2008, pp. 1825-1830. doi:10.1016/j.surfcoat.2007.07.094 
[6] H. Umehara, M. Takaya and S. Terauchi, "Chrome-Free Surface Treatments for Magnesium Alloy," Surface and Coatings Technology, Vol. 169-170, 2003, pp. 666-669. doi:10.1016/S0257-8972(03)00052-5

[7] W. Q. Zhou, D. Y. Shan and E. H. Han, "Structure and Formation Mechanism of Phosphate Conversion Coating on Die-Cast AZ91D Magnesium Alloy," Corrosion Science, Vol. 50, No. 2, February 2008, pp. 329-337. doi:10.1016/j.corsci.2007.08.007

[8] G. Y. Li, J. S. Lian, L. Y. Niu, Z. H. Zhang and Q. Jiang, "Growth of Zinc Phosphate Coatings on AZ91D Magnesium Alloy," Surface and Coatings Technology, Vol. 201, No. 3-4, October 2006, pp. 1814-1820. doi:10.1016/j.surfcoat.2006.03.006

[9] M. Zhao, S. S. Wu, J. R. Luo, Y. Fukuda and H. Nakae, "A Chromium-Free Conversion Coating of Magnesium Alloy by a Phosphate-Permanganate Solution," Surface and Coatings Technology, Vol. 200, No. 18-19, May 2006, pp. 5407-5412. doi:10.1016/j.surfcoat.2005.07.064

[10] Z. C. Kwo and S. S. Teng, "Conversion-Coating Treatment for Magnesium Alloys by a Permanganate-Phosphate Solution," Materials Chemistry and Physics, Vol. 80, No. 1, April 2003, pp. 191-200. doi:10.1016/S0254-0584(02)00481-9

[11] Y. Kuniji and M. Yoshio, "Metal Surface Coating Agent," US Patent 4341 558, 1982.

[12] H. F. Yang, Y. Yang, Y. H. Yang, H. Liu, Z. R. Zhang, G. L. Shen and R. Q. Yu, "Formation of Inositol Hexaphosphate Monolayers at the Copper Surface from a Na-Salt of Phytic Acid Solution Studied by in Situ Surface Enhanced Raman Scattering Spectroscopy, Raman Mapping and Polarization Measurement," Analytica Chimica Acta, Vol. 548, No. 1-2, August 2005, pp. 159-165. doi:10.1016/j.aca.2005.05.061
[13] J. R. Liu, Y. N. Guo and W. D. Huang, "Study on the Corrosion Resistance of Phytic Acid Conversion Coating for Magnesium Alloys," Surface and Coatings Technology, Vol. 201, No. 3-4, October, 2006, pp. 1536-1541. doi:10.1016/j.surfcoat.2006.02.020

[14] X. F. Cui, Y. Li, Q. F. Li, G. Jin, M. H. Ding and F. H. Wang, "Influence of Phytic Acid Concentration on Performance of Phytic Acid Conversion Coatings on the AZ91D Magnesium Alloy," Materials Chemistry and Physics, Vol. 111, No. 2-3, October 2008, pp. 503-507. doi:10.1016/j.matchemphys.2008.05.009

[15] X. F. Cui, Q. F. Li, Y. Li, F. H. Wang, G. Jin and M. H. Ding, "Microstructure and Corrosion Resistance of Phytic Acid Conversion Coatings for Magnesium Alloy," Applied Surface Science, Vol. 255, No. 5, 2008, pp. 2098-2103. doi:10.1016/j.apsusc.2008.06.199

[16] C. H. Liang, R. F. Zheng, N. B. Huang and L. S. Xu, "Conversion Coating Treatment for AZ31 Magnesium Alloys by a Phytic Acid Bath," Journal of Applied Electrochemistry, Vol. 39, No. 10, October 2009, pp. 1857-1862. doi:10.1007/s10800-009-9889-Z

[17] K. H. Yang, M. D. Ger, W. H. Hwu, Y. Sung, Y. C. Liu, "Study of Vanadium-Based Chemical Conversion Coating on the Corrosion Resistance of Magnesium Alloy," Materials Chemistry and Physics, Vol. 101, No. 2-3, February 2007, pp. 480-485. doi:10.1016/j.matchemphys.2006.08.007

[18] M. Zhao, S. E. Wu, P. An and J. R. Luo, "Influence of Surface Pretreatment on the Chromium-Free Conversion Coating of Magnesium Alloy," Materials Chemistry and Physics, Vol. 103, No. 2-3, June 2007, pp. 475-483. doi:10.1016/j.matchemphys.2007.02.058 